\title{
Dry cough and dyspnoea rapidly increasing to respiratory failure in a male smoker
}

\author{
I. Sigala*, I. Kalomenidis*, K. Malagari", D. Rontogianni", G. Kapotsis*, T. Vassilakopoulos*, \\ C. Roussos* and S.A. Papiris*
}

\section{CASE HISTORY}

A 65-yr-old male, current smoker of $>30$ cigarettes $\cdot$ day $^{-1}$ (total smoking history 150 pack-yrs), who was working as a bus driver, presented at the Evangelismos Hospital (Athens, Greece) complaining of increasing breathlessness on exertion and dry cough during the past 2 months. He had no animal exposure and he hadn't travelled abroad during the last few years. His medical history showed arterial hypertension, for which he was receiving treatment with an angiotension-converting enzymeinhibitor (ramipril) plus hydrochlorothiazide, as well as asymptomatic cholelithiasis and prostate hypertrophy for which he was receiving tamsulosin hydrochloride. He did not mention suffering from fever in the last few months.

On admission, the patient was mildly tachypnoeic (22 breaths. $\left.\min ^{-1}\right)$, but apparently in discrete health, with a body temperature of $36.8^{\circ} \mathrm{C}$, pulse rate 85 beats $\cdot \mathrm{min}^{-1}$ and blood pressure $130 / 70 \mathrm{mmHg}$. On chest auscultation, rare fine inspiratory rales were audible over both hemithoraces. He had no clubbing. The tuberculin test was negative. The routine blood analysis and chemistry was normal. Arterial blood gas analysis while breathing room air gave results as follows: arterial oxygen tension $\left(\mathrm{Pa}_{1} \mathrm{O}_{2}\right) 7.95 \mathrm{kPa}$; carbon dioxide arterial tension $\left(\mathrm{Pa}_{\mathrm{a}} \mathrm{CO}_{2}\right) 3.94 \mathrm{kPa} ; \mathrm{pH}$ : 7.45. Chest radiography on admission is shown in figure 1.

Spirometry 2 days later was compatible with a moderate restrictive pattern (forced vital capacity (FVC): $1.52 \mathrm{~L}(48 \%$ predicted); forced expiratory volume in one second (FEV1): $1.28 \mathrm{~L} \cdot \mathrm{sec}^{-1}$ (53.6\% pred); FEV1/FVC $\times 100$ ratio: $84 \%$ ). Lung volumes and diffusing capacity could not be assessed because the patient was unable to cooperate. A bronchoscopy was performed on the 4th day of hospitalisation and no endobronchial abnormalities were found. Bronchoalveolar lavage (BAL) was performed during bronchoscopy and the total cell count was $26.6 \times 10^{9} \cdot \mathrm{L}^{-1}$, with a differential of $82 \%$ macrophages, $12 \%$ lymphocytes and $6 \%$ neutrophils. No infective agents were detected in sputum or in bronchial secretions. Serology for HIV infection was negative, as was the urinary test for Legionella pneumophila and Streptococcus pneumoniae. Serology for common virus, and mycoplasma, ricketsiae and chlamydiae were pending. No underlying immunosuppressive condition was evident.

During the 2-3 days following bronchoscopy, the patient's respiratory condition rapidly deteriorated. Respiratory rate was 34 breaths $\cdot \mathrm{min}^{-1}$ and pulse rate $130 \mathrm{beats} \cdot \mathrm{min}^{-1}$. Arterial blood gases on supplemental oxygen and fractional concentration of oxygen in inspired gas $60 \%$ were: $\mathrm{Pa}, \mathrm{O}_{2} 9.24 \mathrm{kPa} ; \mathrm{Pa}_{2} \mathrm{CO}_{2}$ $4.2 \mathrm{kPa}$; pH 7.44. However, he remained afebrile and the new haematology and biochemical laboratory studies, including total and differential white cell blood count, were within the normal range.

Another chest radiograph obtained on the 7 th day of his hospital stay, is shown in figure 2, and the chest computed tomography (CT) obtained at the same time point is shown in figure 3. During the next few hours, the patient was admitted to the intensive care unit (ICU) due to severe respiratory failure, and a video-assisted thoracoscopic lung biopsy was performed. The histology of the lung biopsy specimen is shown in figure 4.

\footnotetext{
*Dept of Critical Care and Pulmonary Services, and \#2nd Dept of Radiology, National and Capodistrian University of Athens, and "Dept of Histopathology, Evangelismos Hospital, Athens, Greece. CORRESPONDENCE: S.A. Papiris, Dept of Critical Care and Pulmonary Services, $45-47$ Ipsilantou Street, Evangelismos Hospital, GR 10675, Athens, Greece. Fax: 30 2107293470. E-mail: papiris@otenet.gr SUPPORT STATEMENT: this study was supported by the Thorax Foundation, Athens, Greece.
} 


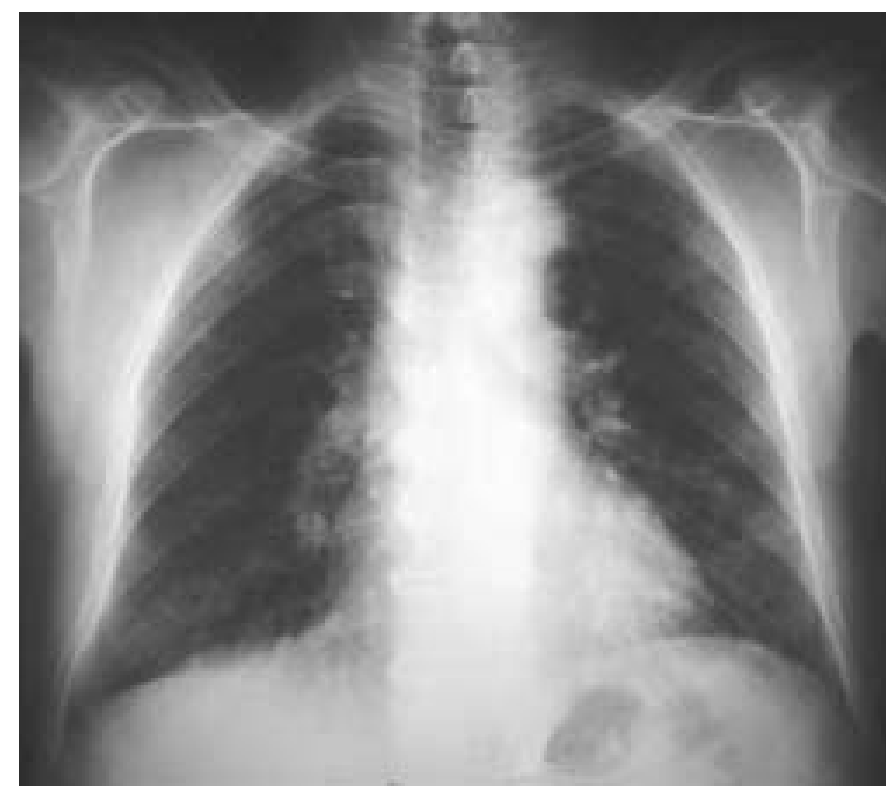

FIGURE 1. Posteroanterior radiograph of the chest on admission.
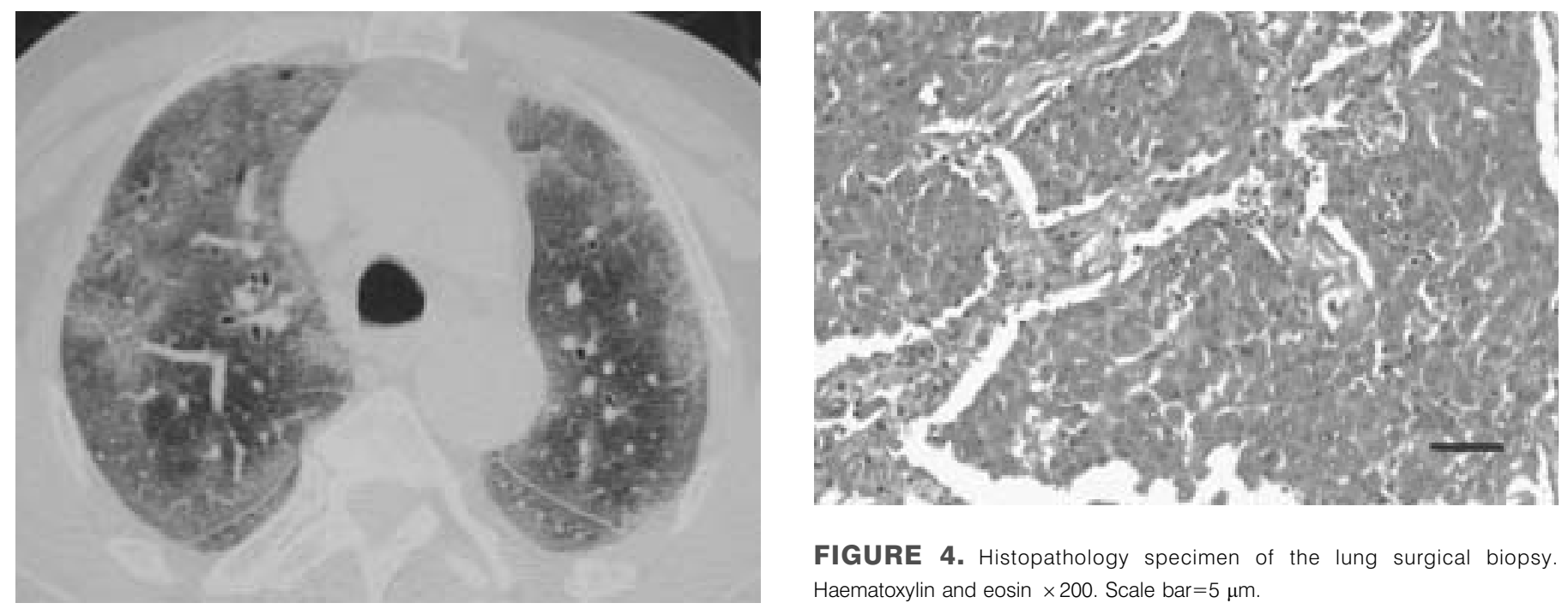

FIGURE 4. Histopathology specimen of the lung surgical biopsy. Haematoxylin and eosin $\times 200$. Scale bar $=5 \mu \mathrm{m}$.
FIGURE 2. Posteroanterior radiograph of the chest taken on the 7th day of the patient's hospital stay.

FIGURE 3. Chest computed tomography scan at the level of the aortic arch.

BEFORE TURNING THE PAGE, INTERPRET THE PATIENT'S HISTORY, CHEST RADIOGRAPHS, CT SCANS AND HISTOLOGY, AND SUGGEST A DIAGNOSIS AND TREATMENT. 


\section{INTERPRETATION}

\section{Chest radiographs and $\mathrm{CT}$ scan}

The posteroanterior chest radiograph on the patient's admission revealed sparse ground-glass opacities bilaterally (fig. 1). The chest radiograph obtained on the 7 th day in hospital (fig. 2) indicated an extension of the ground-glass opacities, with a clear confluent acinar pattern in the right upper lobe. There were no signs of pleural effusion or hilar node enlargement.

The high-resolution CT scan of the chest at the level of the aortic arch (fig. 3) showed diffuse subpleural ground-glass opacities, with a black bronchus sign and no obliteration of the boarders of the lung vessels. In the subpleural areas of the lung, septal thickening and a mild intralobular reticulation was also evident.

\section{Pathology}

The histopathology of the video-assisted thoracoscopic lung biopsy, stained with haematoxylin and eosin (fig. 4), revealed a monotonous infiltrate of large mononuclear cells (intraalveolar macrophages), filling the alveolar spaces and affecting the lung diffusely, accompanied by a mild interstitial inflammation. The histopathology shown in figure 4 is representative for the biopsy as a whole.

\section{Diagnosis: Desquamative interstitial pneumonia (DIP).}

\section{TREATMENT AND CLINICAL COURSE}

The patient was initially treated with an intravenous, empirical, broad-spectrum antibiotic regimen, including a $\beta$ lactam, a macrolide and a quinolone able to cover the majority of common and atypical microbes.

After the histological diagnosis of DIP, the patient was administered a pulse of $i . v$. methylprednisolone $(1 \mathrm{~g})$, followed by i.v. prednisolone $50 \mathrm{mg} \cdot \mathrm{day}^{-1}$ and oral azathioprine $100 \mathrm{mg} \cdot \mathrm{day}^{-1}$. His clinical condition rapidly improved, and he was discharged from ICU 3 days after steroid pulse therapy was administered. Ten days later he was discharged from the pulmonary department without dyspnoea or hypoxaemia and with a normal chest radiograph.

The patient quit smoking and 10 months later was receiving oral prednisolone $20 \mathrm{mg}$ daily and oral azathioprine $100 \mathrm{mg}$ daily. At the time of writing, the patient remains asymptomatic with normal arterial blood gases, spirometry and chest CT scan. A further tapering of his pharmacological treatment is being considered, until it is completely stopped in the next few months.

\section{DISCUSSION}

DIP is one of the seven different clinico-pathological entities included in the group of the idiopathic interstitial pneumonias (IIPs), according to the recent consensus classification, and affects primarily cigarette smokers in their fourth and fifth decades of life [1]. It was first described by LiEBOw et al. [2] in 1965 as a distinct entity and was included in his first classification of the IIPs in 1975 [3]. It soon appeared that patients with DIP had a better prognosis [4], and, therefore, DIP has erroneously been considered to be an early stage of the fibrotic usual interstitial pneumonia. The histological hallmark of DIP is an abnormal accumulation of pigmented macrophages ("smoker's pigment") evenly dispersed within the distal air spaces $[2,3,5]$. The inflammatory process affects the lung almost uniformly, the presence of fibrosis is minimal or absent, and the alveolar architecture is usually well preserved $[1-3,5]$. This clinico-pathological entity might be better described by the term "alveolar macrophage pneumonia", since its characteristic inflammatory infiltrate does not represent desquamation of alveolar epithelial cells, but a true abnormal accumulation of macrophages. DIP is considered to be a more extensive form of the respiratory bronchiolitisassociated interstitial lung disease [1], which is characterised by the presence of pigmented intralumenal macrophages within the first- and second-order respiratory bronchioles.

Clinically, DIP is characterised by an insidious onset of symptoms, such as progressively increasing dyspnoea on exertion and dry cough $[1,4,5]$. Occasionally, DIP may be diagnosed in an asymptomatic individual. The physical examination of patients with DIP is not very helpful as there are few, nonspecific or non-evident findings. Chest auscultation may be normal or reveal bibasilar crackles [1, 5]. Digital clubbing is commonly described. Pulmonary function tests usually disclose a restrictive pattern and reduced diffusing capacity. Arterial blood gas analysis usually reveals mild-tomoderate hypoxaemia. Chest radiographs (normal in 3-22\% of DIP biopsy-proven cases) [2, 4, 6] is mainly characterised by patchy alveolar opacities, with a lower and middle lung zones pre-dilection, but occasionally with a peripheral predominance. Thin-section CT scans always reveal more or less extensive areas of ground-glass attenuation [7]. Irregular lines, traction bronchiectasis and cystic changes may also be seen. BAL fluid from these patients shows an increase in the number of all cell types, with a predominance of macrophages. Since none of the non- or minimally invasive tests provide the diagnostic features of the disease, the diagnosis of DIP should be always be based on lung histology.

The clinical condition of the presented patient rapidly deteriorated leading to respiratory failure, necessitating admission to the ICU department. The differential diagnosis of this case included several conditions, including bacterial or viral pneumonia, tuberculosis, a subacute form of an extrinsic allergic alveolitis, early alveolar proteinosis, drug-related increased permeability oedema [8], acute interstitial pneumonia (Hamman-Rich syndrome), and some other less common or less probable conditions. Conversley, histologically proven DIP may, in some cases, be seen in systemic autoimmune disorders, infections, certain environmental or occupational exposures, and drugs. Empirical treatment with steroids was considered unsafe, since most of the conditions included in the differential diagnosis could have rapidly deteriorated and, thus, lung surgical biopsy was opted for in this case. Lung histology is indeed mandatory in order to distinguish most of the above conditions and secure the diagnosis of DIP. Finally, DIP may present an extended spectrum of clinical behaviour, from asymptomatic and spontaneously resolving, to fulminant or rapidly progressive disease (as in this case). If not promptly recognised and adequately treated DIP may become fatal [9-11].

The ideal treatment of critically ill patients due to accelerating DIP is unknown since clinical trials are lacking and the clinical experience is limited. RYU et al. [4] in their recent review on DIP 
suggested that smoking cessation and steroids should be the mainstay of treatment. The chosen treatment in this case was high-dose pulse corticosteroid therapy, followed by i.v. prednisolone and oral azathioprine, due to the patients severe clinical condition, and this proved life saving. Moreover, smoking cessation and maintenance therapy with steroids and azathioprine was associated with an excellent long-term outcome, as the patient was free of symptoms, respiratory functional impairment and radiographical abnormalities 10 months after the life-threatening event. Smoking cessation is considered essential in the treatment of DIP, and spontaneous improvement has been observed in two out of nine untreated patients [4]. Treatment with conventional doses of steroids is also considered effective in patients with persistent disease, though radiographical deterioration may occur despite treatment $[4,12,13]$. The role of other immunosuppressive drugs in the treatment of DIP is poorly defined.

The prompt response to treatment observed in this case might relate to the timely administration of an intense immunosuppressive regimen, although its clinical course cannot be predicted if handled differently. Recurrence of the disease may occur even many years after therapeutic remission [14] and has also been reported in transplanted lungs [15]. Reports on relapse, however, do not specify whether smoking was a factor in the recurrence of desquamative interstitial pneumonia.

\section{REFERENCES}

1 American Thoracic Society/European Respiratory Society International multidisciplinary consensus classification of the idiopathic interstitial pneumonias. Am J Respir Crit Care Med 2002; 165: 277-304.

2 Liebow AA, Steer A, Billingsley JG. Desquamative interstitial pneumonia. Am J Med 1965; 39: 369-404.

3 Liebow AA. Definition and classification of interstitial pneumonias in human pathology. Prog Respir Res 1975; 8: $1-31$.
4 Ryu JH, Colby TV, Hartman TE, Vassallo R. Smokingrelated interstitial lung diseases: a concise review. Eur Respir J 2001; 17: 122-132.

5 Carrington CB, Gaensler EA, Coutu RE, FitzGerald MX, Gupta RG. Natural history and treated course of usual and desquamative interstitial pneumonia. N Engl J Med 1978; 298: 801-809.

6 Gaensler EA, Goff AM, Prowse CM. Desquamative interstitial pneumonia. N Engl J Med 1966; 274: 113-128.

7 Hartman TE, Primack SL, Swensen SJ, Hansell D, McGuinness G, Muller NL. Desquamative interstitial pneumonia: thin-section CT findings in 22 patients. Radiology 1993; 187: 787-790.

8 Camus P. Drug induced infiltrative lung disease. In: Schwarz MI, King TE Jr, eds. Interstitial lung disease. London, BC Decker Inc, 2003; pp. 485-534.

9 Gould TH, Buist MD, Meredith D, Thomas PD. Fulminant desquamative interstitial pneumonia. Anaesth Intens Care 1998; 26: 677-679.

10 Patel MB. Desquamative interstitial pneumonia: a case presentation. Md Med J 1993; 42: 1119-1122.

11 Flusser G, Gurman G, Zirkin H, Prinslo I, Helmer D. Desquamative interstitial pneumonitis causing acute respiratory failure, responsine only to immunosuppressants. Respiration 1991; 58: 324-326.

12 Hartman TE, Primack SL, Kang EY, et al. Disease progression in usual interstitial pneumonia compared with desquamative interstitial pneumonia. Chest 1996; 110: 378-382.

13 Akira M, Yamamoto S, Hara H, Sakatani M, Ueda S. Serial computed tomographic evaluation in desquamative interstitial pneumonia. Thorax 1997; 52: 333-337.

14 Lipworth B, Woodcock A, Addis B, Turner-Warwick M. Late relapse of desquamative interstitial pneumonia. Am Rev Respir Dis 1987; 136: 1253-1255.

15 Verleden GM, Sels F, Van Raemdonck D, Verbeken EK, Demedts M. Possible recurrence of desquamative interstitial pneumonitis in a single lung transplant recipient. Eur Respir J 1998; 11: 971-974. 